\title{
PRIMENA SOFTVERA U FITNES INDUSTRIJI
}

\section{Aleksandar Gadžićc ${ }^{*}$, Aleksandar Živković1, Zdravko Aničić ${ }^{2}$}

\author{
1 Univerzitet Singidunum, \\ Beograd, Srbija \\ ${ }^{2}$ Fakultet sporta i fizičkog vaspitanja, \\ Univerzitet u Beogradu, \\ Beograd, Srbija
}

\begin{abstract}
Rezime:
Savremeni čovek sve više živi sedentarnim načinom života. Ljudi danas provode sate gledajući televiziju, radeći za računarom ili jednostavno provode vreme neaktivni. Ipak, pod uticajem sve prisutnijih socijalnih medija pokrenut je značajan broj sajtova koji se bave posebnim režimima ishrane, angažovanjem ličnih trenera, kupovine fitnes opreme, tako da je danas članstvo u nekom fitnes klubu postalo skoro uobičajena stvar za mnoge ljude. Ova potreba čoveka modernog doba dovela je do stvaranja globalne fitnes industrije, čija se vrednost danas meri bilionima dolara. Savremeni softveri omogućili su ljudima da lako prate efekte svog treninga putem mobilnih aplikacija i wearable tehnologije. Predviđanja su da će ove tehnologije imati sve veću primenu i rast u fitnes industriji. Ipak, potrebno je napomenuti da tehnologija ne može u potpunosti da zameni živog fitnes stručnjaka u davanju najboljih saveta i instrukcija za vežbanje.
\end{abstract}

Ključne reči:

zdravlje i fitnes, socijalne mreže, wearables, mobilne aplikacije.

\section{UVOD}

Od pojave prve komercijalne vežbaonice (gym) u Briselu 1840. godine do današnjih dana, fitnes industrija je evoluirala u jedan od najbrže rastućih biznisa današnjice. Pravi proboj u fitnes industriji desio se tokom 80-ih godina prošlog veka otvaranjem lanaca vežbaonica kao što su 24 Hour Fitness (1983) i LA Fitness (1984). Takođe, pojava video tehnologije dovela je do planetarne popularnosti Džejn Fonda video časova vežbanja od kojih je nastao ceo pokret Aerobik.

Megalanci vežbaonica postoje i danas, ali kao kod mnogo drugih stvari, današnji potrošači traže više individualni i lični pristup, tako da je tokom 1990-ih i 2000-ih godina došlo do otvaranja brojnih, manjih klubova zdravlja (health clubs), do povećane tražnje za ličnim trenerima i pojave drugih, specijalizovanih vežbaonica tipa Cross-Fit, Crunch Fitness, Fit Body Boot Camp i drugih franšiza.

U poređenju sa ranijim generacijama, današnja populacija živi više sedentarnim načinom života. Ljudi danas provode sate gledajući televiziju, radeći za računarom ili jednostavno provode vreme neaktivni. Takođe,
Odgovorno lice:

Aleksandar Gadžić

e-pošta:

agadzic@singidunum.ac.rs 
ljudi se sve nekvalitetnije hrane, a povrh svega količinski unose više hrane (kalorija) nego što su njihove stvarne potrebe. Nažalost, ovakav način života sa sobom donosi i velike posledice po zdravlje.

Prema podacima Svetske zdravstvene organizacije (WHO) za 2016. godinu, skoro 40\% odraslih u svetu ima višak kilograma, dok je $13 \%$ gojazno. Posebno su zabrinjavajući podaci da je više od 41 milion dece uzrasta do pet godina spadalo u kategorije sa viškom kilograma ili gojazni [1]. Prema istom izvoru, fizička neaktivnost se javlja kao četvrti faktor mortaliteta na globalnom nivou.

\section{MODERNI RAZVOJ FITNES INDUSTRIJE}

\section{Uticaj socijalnih medija, fitnes i zdravstvenih pokreta}

Nakon fitnes buma iz 80-ih godina prošlog veka, koji je maksimalno iskoristio video kao medij, svedoci smo velikih promena prvenstveno u komunikaciji zbog postojanja fenomena socijalnih medija/mreža. Socijalne mreže i mediji su postali moćno sredstvo promocije raznih životnih stilova, među kojima fitnes i zdravlje zauzimaju posebno istaknuto mesto. Samo u SAD-u više od polovine stanovništva ima bar jedan profil na socijalnim mrežama, dok je oko 86\% mladih (od 18 do 29 godina) aktivno na nekoj od društvenih mreža [2]. Uz tako lak način da se bude u kontaktu sa drugima, sve više ljudi se okreće socijalnim mrežama kao što su Facebook, Instagram, Twitter i Pinterest kako bi došli do informacija o zdravlju i fitnesu.

Ljudsko ponašanje je pod velikim uticajem socijalnog konteksta. Veliki broj health \& fitness influensera sa Instagram-a, Facebook-a i Twitter-a promovišu vežbanje i zdravu ishranu i motivišu ljude da ih prate. Generacije rođene posle 2000. godine (milenijalci) su posebno podložni uticaju sadržaja koji na društvene mreže postavljaju poznate ličnosti (celebrity), prijatelji i javnost uopšte. U tom smislu postaje sve teže ignorisati konstantan priliv sadržaja kojim se oni ohrabruju da zaprate fitnes blog, pretplate se na program vežbanja, ili jednostavno kupe neki deo sportske opreme.

Široki pristup socijalnim medijima je pružio šansu fitnes entuzijastima koji su želeli da pokrenu biznis. Influenseri, kao što je na primer Kayla Itsines, iskoristili su socijalne medije kako bi stvorili veoma uspešne brendove. Nakon samo 12 meseci pisanja bloga o fitnesu i ishrani na Instagramu, Kayla ima oko 1,7 miliona pratilaca i procenjenu zaradu od 46 miliona dolara [3].

Ranije pomenuti problemi modernog čoveka u vezi sa fizičkom neaktivnošću i lošem načinu ishrane ipak su pokrenuli značajan broj sajtova koji se bave posebnim režimima ishrane, angažovanjem ličnih trenera, kupovine fitnes opreme, tako da je danas članstvo u nekom fitnes klubu postalo skoro uobičajena stvar za mnoge ljude. Ova želja, i pre svega potreba čoveka modernog doba, dovela je do stvaranja globalne fitnes industrije čija se vrednost danas meri bilionima dolara.

Prema statističkim podacima američkog biroa rada (Buerau of Labor Statistics) za 2014. godinu, samo u Americi je bilo registrovano preko 34.000 fitnes centara koji su ostvarili prihod od 24,2 milijarde dolara. Istovremeno, u tim centrima bilo je zaposleno 533.200 ljudi [4].

\section{GLOBAL WELLNESS ECONOMY: $\$ 3.7$ trillion in 2015}

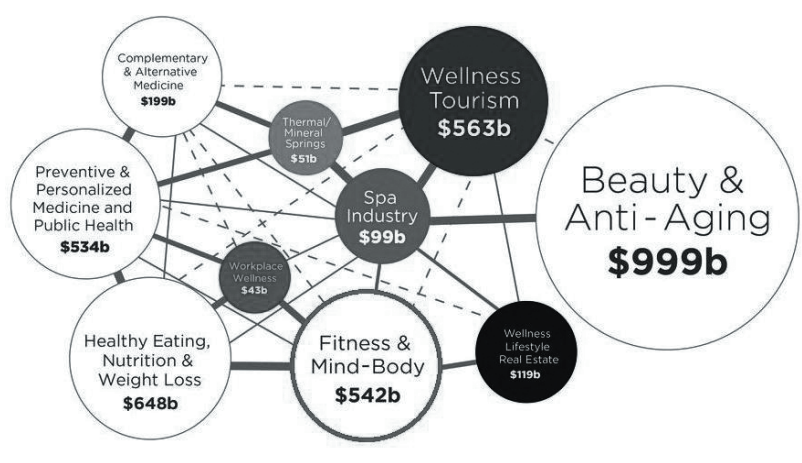

Slika 1. Vrednost globalne wellness ekonomije u 2015. godini [5].

Prema istraživanju Global wellness instituta, vrednost fitnes industrije (uz dodatak mind-body sektora) $\mathrm{u}$ 2015. godini iznosila je ogromne 542 milijarde dolara u svetu (Slika 1).

Jedna od prvih mogućnosti primene specijalizovanih softvera u fitnes industriji bila je mogućnost elektronskog menadžmenta fitnes klubova. Naime, preduzimljive privatne kompanije brzo su reagovale na sve rastući biznis fitnes industrije, tako da se već 1998. godine na tržištu pojavio Flexware softver za menadžment fitnes klijenata (klubova, centara, teretana) koji im je omogućio punu administraciju podataka, evidenciju članstva, finansijsko knjigovodstvo itd. [6].

U današnje vreme poznavanje informacionih tehnologija je od suštinske važnosti u fitnes industriji.

Prema Seni [7], svaki ulagač ili preduzetnik u fitnes industriji mora da poznaje izazove sa kojima će se sresti jer je konkurencija veoma oštra:

- rat cenama je nemilosrdan. Velike kompanije ulažu veliki novac u reklamu, što mali preduzetnici ne mogu da priušte; 
- objekti kojima rukovode univerziteti, opštine ili medicinski centri imaju velike budžete, veći pristup potencijalnim klijentima i u nekim slučajevima preporuke od strane lekara (medicinske ustanove);

- personalni treneri mogu da drže privatne sate u domovima klijenata;

- onlajn opcije su svakog dana sve prisutnije. Klijenti jednostavno mogu da gledaju video zapise ili čak vežbačke grupe uživo i da se uključe u virtuelne zajednice;

- postojanje mobilne tehnologije sa biometrijskim podacima (softveri) omogućava klijentima da dobiju informacije o svom vežbanju u realnom vremenu, što čini personalne trenere ili vežbačke grupe manje potrebnim.

\section{Aktuelni tipovi softvera u fitnes industriji}

Pored socijalnih medija, postoji čitavo bogatstvo informacija na internetu i mnogi ljudi biraju da sami odlučuju koji program vežbanja će da izaberu, umesto da im to odredi profesionalac. Uopšte, mediji danas igraju značajnu ulogu u oblikovanju fenomena health \& fitness.

Na primer, tržište je preplavljeno magazinima koji su tematski posvećeni health \& fitness-u ili suplementaciji u sportu i fitnesu. Na internetu postoje online health \& fitness forumi, i naravno tu je i nezaobilazni pretraživač Google - koji će pružiti odgovor na bilo koje pitanje u vezi sa health \& fitness-om.

U prošlosti su fitnes klubovi bili mesto gde su klijenti dolazili i imali mogućnost da vežbaju po svom ličnom nahođenju. U savremenim fitnes klubovima taj trend je uveliko promenjen. Klijenti danas imaju mogućnost korišćenja sofisticiranog i personalizovanog praćenja treninga koje se zasniva na primeni kompjuterske tehnologije.

U osnovi, fitnes softveri se danas dele u dve osnovne kategorije:

- Club Management Software i

- Personal Trainer Software

Upravo primenom Google pretraživača danas se može proveriti i videti lista najpopularnijih fitnes softvera u industriji i ta lista za 2018. godinu ima 46 recenziranih softvera [8]. Najbolje rangirani softver (786 recenzija), Acuity Scheduling, ima karakteristike ličnog asistenta za lični raspored. Omogućava maksimalnu efikasnost iskorišćenosti vremena, dostupnost klijentima u realnom vremenu, plaćanje unapred putem Stripe, Paypal ili Authorize.net platforme.
Opcije koje nude softveri sa liste odnose se na:

- Attendance Tracking

- Billing \& Invoicing

- Check-in Manager

- Class Management

- Contract Management

- Employee Management

- Event Management

- Inventory Management

- Marketing Management

- Membership Management

- Point of Sale (POS)

- Reservations Management

Ipak, i pored bogatstva ponude koju pružaju savremeni, ,state of the art" fitnes centri i podatka da stalno raste broj članstva u njima, činjenica je da procenat onih članova koji brzo prekidaju sa vežbanjem ili čak nikada ne idu u vežbaonicu nakon što se učlane jeste veoma visok (oko 67\%!) [9].

Detaljnim istraživanjem tržišta u fitnes industriji nije promakao podatak da se većina tih klijenata okreće ka internetu kako bi se informisali o najboljim načinima vežbanja za njih. Ispostavilo se da takvi klijenti više vole da vežbaju kod kuće zahvaljujući dostupnosti onlajn fitnes programa. Dostupni su brojni celebrity treneri, kao i popularni programi vežbanja koji ne zahtevaju skupu opremu i omogućavaju lakše planiranje vežbačke rutine.

S obzirom na visoku dinamičnost fitnes industrije, tržište je veoma brzo reagovalo na ovakav trend kada su u pitanju klijenti koji preferiraju vežbanje kod kuće. Naime, prema slobodnim procenama, danas je u opticaju oko 8.000 fitnes aplikacija koje su dostupne za preuzimanje.

Popularnost takozvanih wearables ili u slobodnom prevodu mobilnih softvera, značajan je faktor koji doprinosi rastu onlajn fitnes programa. Wearables takođe omogućavaju „šerovanje” putem socijalnih mreža sa prijateljima, kolegama vežbačima ili sa onlajn trenerom, što doprinosi da vežbači zadrže fokus, motivaciju i da pruže podršku jedni drugima.

Da popularnost wearables tehnologije nije samo puka prolazna pomama za novim tehnološkim spravicama, potvrđuju i činjenice da veoma ozbiljne svetske ekipe koriste ove tehnologije u svojim treninzima. $\mathrm{Na}$ primer, kompanija Adidas je lansirala proizvod miCoach Smart Ball u maju 2014. godine. „Pametna lopta” (The smart soccer ball) je bila rezultat istraživačko-razvojnog 
poduhvata osmišljenog da se pomogne da nemački nacionalni tim uz primenu tog sistema trenira „pametnije". Lopta je imala ugrađen senzor koji detektuje brzinu, obrtaje, pravac udarca i leta lopte, kao i prenos podataka putem Bluetooth tehnologije ka trenerovom ili igračevom telefonu. Korisnici su mogli da vide sve merene varijable putem Smart Ball aplikacije. Sistem je koristio podatke da analizira izvedbu igrača i da pruži savet kako igrač može da poboljša svoje fudbalsko umeće. Takođe, aplikacija je nudila savete za program treninga i omogućavala je praćenje napretka igrača.

Drugi značajan primer koji pokazuje ozbiljnost namera velikih kompanija da investiraju u savremene mobilne softvere je kompanija Under Armour, koja je u januaru 2016. godine predstavila svoj koncept $\mathrm{He}$ althBox connected fitness system, kojim se vežbač povezuje sa svim drugim Under Armour smart uređajima, što omogućava korisnicima da pristupe podacima i pokazateljima svog zdravstvenog i fitnes statusa sa jednog mesta. Sistem integriše wearables kao što su pametne bežične slušalice, pametne patike, pametne narukvice za praćenje srčanog rada, kao i UA Heart Rate grudne trake za monitoring srčane frekvencije. Korisnik može da vidi sve podatke na UA Record smartphone aplikaciji, kao i da podeli te podatke sa prijateljima, trenerom, doktorom i sl.

Under Armour planira da postane vodeća kompanija u Connected fitness-u, i pored akvizicija iz 2015. godine Endomondo i MyFitnessPal, kompanija je 2013. godine kupila i MapMyFitness aplikaciju za 150 miliona dolara. Predviđanja te kompanije pokazuju značajan rast prodaje „pametne” sportske opreme (Slika 2).

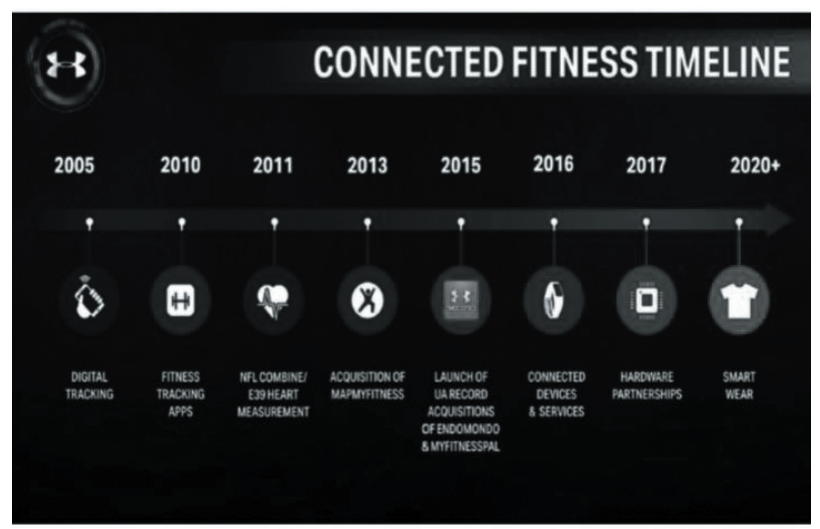

Slika 2. Predviđanje rasta prodaje sportske opreme Connected fitness od strane kompanije Under Armour [10].

\section{BUDUĆNOST FITNES SOFTVERA}

Brojni su faktori koji igraju važnu ulogu uspehu health and fitness industrije danas. Ono šta se posebno ističe, a što je zajedničko za sve faktore, jeste činjenica da se menja ponašanje klijenata. Klijenti (potrošači) su sve više informisani i svesni zdravstvenih rizika, kao i važnosti održavanja dobrog zdravlja.

Relevantni podaci govore o trendu konstantnog rasta broja novih članova u fitnes klubovima, tako da je samo na tržištu Amerike 2000. godine bilo 32,8 miliona članova, a taj broj za 2016. godinu je iznosio 57,25 miliona [11].

Prognoze rasta u nekim zemljama su optimistične, tako za Veliku Britaniju (UK Fitness Industry Report) podaci govore da je za period od 12 meseci (od marta 2016. do marta 2017. godine) došlo do porasta od 4,6\% u broju fitnes centara, $5,1 \%$ povećanja klijenata i porasta tržišne vrednosti od 6,3\% [12]. Prema istom izvoru, očekuje se dalji rast ovog sve značajnijeg segmenta industrije.

Ipak, i pored evidentnog rasta procenata novih klijenata u fitnes centrima, ranije pomenuti podaci ukazuju da veliki broj tih članova veoma retko posećuje fitnes klubove čiji su članovi. To su upravo činjenice koje govore u prilog prognozama velikog rasta primene novih tehnologija, pre svega mobilnih aplikacija i wearable tehnologija.

Očekivanja su da kategorija Smart sports equipment ostvari rapidan rast, tako da se procenjuje da će udeo digitalne sportske opreme u ukupnom tržištu sportske opreme biti 7,5\% do 2020. godine, što će predstavljati rast od 4,6\% u odnosu na 2015. godinu. Očekuje se da će aktivni sportisti i rekreativci u većem broju početi da koriste connected fitness systems, kao i da će pametna sportska oprema biti finansijski mnogo pristupačnija.

Posebnu pažnju zaslužuje sve veći broj mobilnih aplikacija, s obzirom na činjenicu da se lako preuzimaju i instaliraju na pametne telefone, a prema nekim procenama danas postoji oko 40.000 health \& fitness mobilnih aplikacija na internetu.

Mobilne aplikacije korisniku omogućavaju lako praćenje parametara treninga, a u zavisnosti od brojnih i raznovrsnih opcija nude baze vežbi, posebno osmišljenih treninga za razvoj brzine, snage, izdržljivosti ili jednostavno poboljšanje opšteg nivoa fitnesa. 


\begin{tabular}{lll} 
Segment & CAGR & Period \\
\hline Smart Sports Coaching Platforms & $51 \%$ & $2014-2021$ \\
\hline Smart Sports Fitness Trackers & $22 \%$ & $2014-2019$ \\
\hline Sports Equipment & $3 \%$ & $2015-2020$ \\
\hline
\end{tabular}

Slika 3. Predviđanje rasta prodaje „pametne" sportske opreme [13].

\section{ZAKLJUČAK}

Ranije je pomenuto da današnji način i tempo života predstavljaju značajan rizik za nastanak raznih zdravstvenih tegoba i brojne zemlje su preduzele čitav niz mera. Tako na primer, većina evropskih zemalja su razvile različite pristupe razvijanju strategija za promovisanje fizičkog vaspitanja i fizičke aktivnosti uopšte. Poseban kvalitet tih strategija odnosi se na činjenicu da su vlade evropskih zemalja prepoznale važnost i ozbiljnost problema, tako da su promotivni napori usmereni pre svega na školsku populaciju. Uspostavljene nacionalne strategije najčešće se zasnivaju na rezultatima prethodnih strategija ili novijih istraživanja u polju fizičkog vaspitanja i fizičke aktivnosti [14].

Kada je u pitanju odrasla populacija, Evropska komisija je još 2007. godine uspostavila koherentnu i sveobuhvatnu strategiju kako bi se adekvatno pristupilo rešavanju problema prekomerne težine i gojaznosti usvajanjem White Paper A Strategy on Nutrition, Overweight, and Obesity-related health issues, koji se fokusira na akcijama koje se mogu preduzeti na lokalnom, regionalnom, nacionalnom i evropskom nivou u cilju smanjenja rizika povezanih sa nepravilnom ishranom $i$ smanjenom fizičkom aktivnosti [15].

Na kraju, može se konstatovati da je tehnologija nešto na šta moderan čovek mora i treba da se oslanja. Međutim, uvek treba imati na umu da je tehnologija sredstvo kojim pokušavamo lakše doći do cilja, a ne svemoguće rešenje, posebno u oblasti fizičkog vežbanja.

Nedostatak fitnes softver solucija ogleda se u činjenici da, ma koliko isti delovali savršeno, oni nikada ne mogu da zamene fitnes stručnjaka koji ličnom, profesionalnom ekspertizom može da uradi trenutne korekcije određenog programa vežbanja. Naravno, činjenica je da kvalitetan fitnes stručnjak nije uvek dostupan svakom klijentu, ali kada se u obzir uzmu eventualni rizici pogrešnih vežbi ili opterećenja, jasno je da prednost ima „Živa reč", odnosno direktna komunikacija sa stručnjakom.

\section{LITERATURA}

[1] World health organization, „Obesity and overweight", 2018, dostupno na http://www.who.int/mediacentre/ factsheets/fs311/en/

[2] E.C. Stevens, „Social Media and Fitness: The Good, the Bad, and the Ugly", 2017, dostupno na http:// breakingmuscle.com/fitness/social-media-and-fitness-the-good-the-bad-and-the-ugly

[3] E. Lord, „How health and fitness became a trillion dollar industry", 2017, dostupno na https://www. lightspeedhq.com/blog/2017/01/how-health-fitnessbecame-trillion-dollar-industry/

[4] Bureau of Labor Statistics, "NAICS 713940 - Fitness and Recreational Sports Centers", 2016, dostupno na https://www.bls.gov/oes/current/naics5

[5] Global wellness institute, [online]. Dostupno na: https://www.globalwellnessinstitute.org/press-room/ statistics-and-facts/

[6] Flexware, „Client management systems“, 2018, dostupno na http://www.flexware.net.au/index.html

[7] M. Sena, „Fitness Industry Analysis 2018 - Cost \& Trends", https://www.franchisehelp.com/industryreports/fitness-industry-analysis-2018-cost-trends/

[8] Fitness Software, „Captera The Smart Way to Find Business Software", 2018, dostupno na https://www. capterra.com/fitness-software/?utf8=\%E2\%9C\%93\& users $=\&$ sort_options $=$ Most+Reviews Nicole, "Title of paper with only first word capitalized," J. Name Stand. Abbrev., in press.

[9] The Disruptors of Sports: Smart Sports Equipment, 2018, dostupno na https://www.fungglobalretailtech.com/research/disruptors-sports-smart-sports-equipment/

[10] The Investors Studio, [online]. Dostupno na: https:// www.theinvestorsstudio.com/single-post/2017/06/27/ Under-Armours-Mobile-Commerce-Machinery

[11] Statista, „Total number of memberships at fitness centers / health clubs in the U.S. from 2000 to $2016^{\text {", }}$, dostupno na https://www.statista.com/statistics/236123/us-fitness-center--health-club-memberships/

[12] State of the UK Fitness Industry Report, 2017, dostupno na http://www.leisuredb.com/2017-fitness-pressrelease

[13] Winter Green Research [online]. Dostupno na: https://www.fungglobalretailtech.com/research/ disruptors-sports-smart-sports-equipment/

[14] Physical Education and Sport at School in Europe. Dostupno na: http://eacea.ec.europa.eu/education/ eurydice

[15] WHITE PAPER ON A Strategy for Europe on Nutrition, Overweight and Obesity related health issues Dostupno na: http://ec.europa.eu/health/archive/ph_determinants/ life_style/nutrition/documents/nutrition_wp_en.pdf 